\title{
Fraser syndrome presenting as bilateral renal agenesis in three sibs
}

\author{
J BURN* AND R P MARWOOD $\dagger$
}

From *the MRC Clinical Genetics Unit, Institute of Child Health, 30 Guilford Street, London WCIN 1EH; and $\dagger$ the Department of Obstetrics and Gynaecology, St Mary's Hospital, Harrow Road, London W9 3RL

SUMmaRy A family is reported in which three sibs had bilateral renal agenesis. They shared the features of Fraser syndrome, though only one had cryptophthalmos.

In 1962, Fraser $^{1}$ described four cases of cryptophthalmos and multiple malformations in two sibships. In each, one was stillborn. Francois ${ }^{2}$ noted four cardinal signs: cryptophthalmos, anomalies of the nose and ears, syndactyly, and malformations of the external genitalia. Laryngeal atresia and renal agenesis were less constant features. His review of ten families with two or three affected members strongly suggested autosomal recessive inheritance. This view was supported by the report by Azevedo et $a l^{3}$ of four cases in two families with consanguineous parents, and a family with three affected sibs described by Emberger et al. ${ }^{4}$

We report a family with three severely affected sibs, only one of whom had cryptophthalmos which was unilateral, whereas bilateral renal agenesis was common to all three.

\section{Case report}

A mother (I $\cdot 1$, fig 1) presented for counselling in 1971 after the delivery of a second stillborn child. The first (II 1 ), born two years previously, was a Received for publication 26 November 1981

$\uparrow$ Present address: Department of Obstetrics and Gynaecology, Westminster Hospital, London SW1P 2AP.

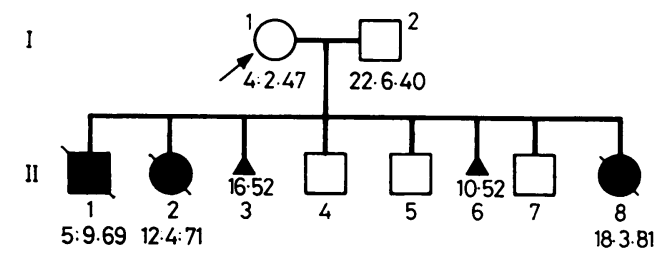

Stillbirth with multiple anomalies including bilateral renal agenesis

- Miscarriage

FIG 1 Pedigree of family. male delivered at 43 weeks weighing $2 \cdot 28 \mathrm{~kg}$. Necropsy had revealed bilateral renal agenesis with low set ears and Potter's facies. In addition, there was a univentricular heart, marked kyphoscoliosis, failure of ossification of the cranium, and complete absence of one eye.

The second infant (II $\cdot 2)$ weighed $2883 \mathrm{~g}$ at 41 weeks and again had bilateral renal agenesis. The vagina was absent and the ovaries cystic. The thymus was absent, but the heart was normal. Other features were syndactyly on all four limbs, facial asymmetry, and upward slanting eyes. The larynx was atretic and, with pulmonary hypoplasia, resulted in intrapartum asphyxia. Both this infant and the mother had a normal 46,XX karyotype.

Ultrasonography confirmed that both parents had normal kidneys. They were given an empirical recurrence risk of 1 in 8 for a further child with renal agenesis.

Her third pregnancy ended in a miscarriage at 16 weeks, after which she gave birth to two healthy

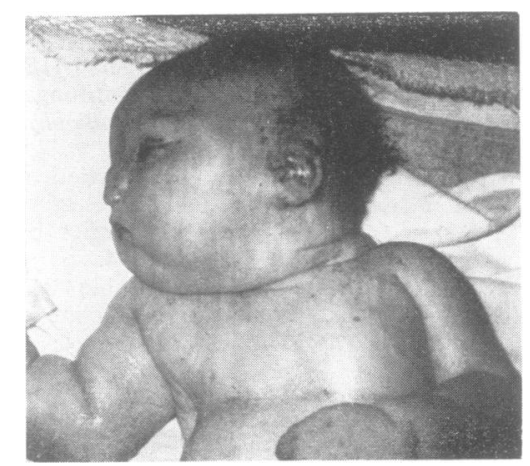

FIG 2 Case II 8. Potter's facies and defect of upper eyelid. Note furrow on forehead. 
sons. After a further miscarriage, a third normal boy was delivered.

In her final pregnancy, absence of the fetal kidneys was confirmed on ultrasound examination in the third trimester. She proceeded to term. The infant, a girl (II·8), weighed $3162 \mathrm{~g}$ and died after one hour. Necropsy revealed features of disturbed development of the urogenital sinus, with bilateral renal agenesis, a solid uterine anlage, absence of the vagina, large cystic ovaries, and an undifferentiated genital tubercle. In addition there was symbrachydactyly, laryngeal obstruction, lax joints, and an asymmetrical skull. Fig 2 illustrates the typical Potter's facies and upward slanting eyes. There was deficiency of the medial third of the left upper eyelid, resulting in direct transition from skin to sclera. Both globes were otherwise normal.

\section{Discussion}

The first affected child in this sibship (II-1) was an index case (case 25) in the family study of renal agenesis reported by Carter et al. ${ }^{5}$ In the discussion, it was noted that "Case 25 and his sister may be examples of the ... probably recessive cryptophthalmos syndrome". Sadly, the birth of the third affected sib has confirmed this suspicion.

Clearly, Fraser syndrome is a disorder with protean manifestations. In those cases which are viable, cryptophthalmos is the most striking feature. However, preference for the term 'cryptophthalmos syndrome ${ }^{6}$ has tended to obscure the other features. The review by Emberger et $a l^{4}$ includes all the features observed in the present family, particularly renal agenesis, primitive sex organs, syndactyly, and laryngeal obstruction. Features not seen in the family reported here include atresia of the anus and external auditory canal and myelomeningocele.

It is noteworthy that cryptophthalmos was present in only one infant and was unilateral. The logical 'handle' for attempting to identify a syndrome in published reports was the renal agenesis common to all three, yet the major reference works do not index Fraser syndrome under this heading. McKusick $^{7}$ makes reference only to the paper of Winter $e^{2} a l^{8}$ (26740), in which four female sibs were observed to have renal hypoplasia or aplasia, anomalies of the internal genitalia, especially vaginal atresia, and in the two surviving sisters, retardation, a 'pinched' nose, and deafness owing to a defect of the ossicles of the middle ear with stenosis of the external auditory meatus. It seems likely that this family also represents a variant of Fraser syndrome.

Carter et $a l^{5}$ divided their index cases into two categories; category 1 in which associated malformations were consistent with forming part of a developmental field defect, and category 2 for those cases with heart, spinal (other than sacral), facial, tracheooesophageal, and other anomalies. The 79 category 1 probands had 141 sibs of whom five were similarly affected. Five others had neural tube defects. The 29 category 2 patients had two of 58 sibs affected, one of which was II. 2 of the present report.

After the birth of a child with bilateral renal agenesis, fetal ultrasonography during the next pregnancy should be offered in view of the 1 in 30 empirical recurrence risk for renal agenesis. A neural tube defect should also be sought.

If, in addition to defects of the caudal region, the first case is noted to have other malformations, Fraser syndrome should be considered. The offer of fetoscopy may be indicated to look for eye, ear, finger, and genital anomalies, to help with the recognition of a child who would be viable but severely malformed.

We are grateful to Mr G D Pinker for permission to prepare this report, and to Professor C O Carter for his encouragement and advice.

\section{References}

1 Fraser CR. Our genetic 'load'. A review of some aspects of genetical variation. Ann Hum Genet 1962;25:387-415.

2 Francois J. Syndrome malformatif avec cryptophthalmos. Acta Genet Med Gemellol 1969;18:18-50.

3 Azevedo ES, Biondi J, Ramelho LM. Cryptophthalmos in two families from Bahia, Brazil. J Med Genet 1973;10: 389-92.

4 Emberger JM, Pincemin D, Taib J, Caderas de Kerleau J. Etude anatomique d'une observation de cryptophthalmie familiale. J Genet Hum 1976; suppl 24:23-9.

5 Carter CO, Evans K, Pescia G. A family study of renal agenesis. J Med Genet 1979;16:176-88.

- Smith DW. Recognisable patterns of human malformations. 2nd ed. Philadelphia: Saunders, 1976: 121.

7 McKusick VA. Mendelian inheritance in man. 5th ed. Baltimore, London: Johns Hopkins University Press, 1978.

8 Winter JSD, Kohn G, Mellman WJ, Wagner S. A familial syndrome of renal, genital and middle ear anomalies. $J$ Pediatr 1968;72:88-93.

Requests for reprints to Dr J Burn, MRC Clinical Genetics Unit, Institute of Child Health, 30 Guilford Street, London WC1N 1EH. 